\title{
Monitoring of radical thermocatalyzed breakdown of polychlorinated compounds
}

\author{
A. Bacaloni ${ }^{1}$, F. Benvenuti ${ }^{2}$, R. Curini ${ }^{1}$, A. Gentili ${ }^{1}$ and S. Materazzi ${ }^{1, *}$ \\ ${ }^{1}$ Dept. of Chemistry, University "La Sapienza”, Rome, Italy \\ ${ }^{2}$ I.S.P.E.S.L., Rome, Italy
}

\begin{abstract}
Disposal of polychlorobiphenyls (PCBs) is a current problem still far from a really satisfactory solution. Because of the wide use and the chemical inactivity, the PCB amount to be treated is considerably large. In this paper, the setting-up of a methodical catalytic pyrolysis of polychlorinated compounds is proposed. The monitoring of the final decomposition products by analytical techniques, such as GC and coupled TG-FTIR, allowed to optimize the reaction temperature: the encouraging results, the lower operative temperatures with respect to previous systems and the favourable prospects regarding the environmental impact make this methodology open to practical applications at a relative low cost.
\end{abstract}

Keywords. Thermocatalyzed breakdown - polychlorinated compounds - radical oxidation.

\section{Introduction}

The problems related to the increase and the disposal of polychlorobiphenyls (PCBs) are still real because of the large estimated worldwide stock, the chemical stability of these compounds and their toxicological characteristics [15].

PCBs have been employed in different fields, due to their facility of production and utilization; the main quantitative use is certainly as a dielectric fluid in electrical capacitors and transformers, for their inherent characteristics of inflammability and thermal stability. However, the chemical and biological inertia of these molecules make the PCBs contamination one of the most widespread problem in the world; their persistance and accumulation through the food chain have caused events of bioconcentration, with collective toxic sometimes clamorous effects.

Many pathologies are correlated to PCB intoxication, with prevailing cutaneous and hepatic effects [6-9]. Actually, there is not a rilevant acute toxicity, but long term effects should be considered.

Indeed, the International Cancer Research Agency (IARC) believes these substances represent a probable cancerous risk for man (classified as $2 \mathrm{~A}$ class).

It should also be remembered that in PCB technical mixtures can often be found traces of polychlorotriphenyls (PCTs), polychlorodibenzofurans (PCDFs) and polychlorodibenzodioxins (PCDDs).

Even though for several years it was prohibited in the European Community to sell products and equipments containing PCBs, the structures still operative can be utilized until their functional life span.

This fact implies that, for several years to come, the disposal problem of PCB stores will remain a current issue. Furthermore, it should be considered that while for some applications (self copying and recycled paper) it is now possible to establish limits in the PCB content (ppm amount), in some fields the development of disposal requests is just starting out (electrical transformers).

At present, the main PCB disposal method consists in the dumping in controlled sites; thermodisposal or different treatments are less effective [10,11].

The storage in controlled areas presents serious difficulties both in locating appropriate sites and for the particular characteristics the area should have. Moreover, it is difficult to control the slow release of the pollutants with time, leading to possible groundwater contamination, because of the stability and the unknown initial concentrations of these products.

Advanced processes of incineration are already operative, with more than satisfactory results: the emission recorded can be even less than those found in urban incinerators. In this case however there is essentially an economic problem, due to the high temperatures involved, the complex operation of the plant and the process duration. The toxicological aspects of the non-thermal processes (biodegradation) are not sufficiently exhaustive. Moreover, these systems present application limits that confine their importance to specific situations. 
Owing to the low chemical reactivity of PCBs, the toxicity of the minor products deriving from the thermodecomposition and the need to use very high temperatures in the incinerators, new disposal alternative systems (as chemical treatments or improved thermal decompositions) have been investigated [12-43].

Referring to the literature, primary and secondary haloalkanes and polychloroethenes can be easily oxidated by superoxides $\left(\mathrm{O}_{2}^{\circ-}\right)$ in aprotic media [44,45], but chlorobenzene and aromatic monohalogenate hydrocarbons do not react at significant speed [46]; this led to believe that all the aromatic halogenate hydrocarbons behave in the same way. However, as Sugimoto et al. evidenced [20], hexachloro-, pentachloro-, tetrachloro- and trichlorobenzene as well as decachlorobiphenyl and other "heavy" polychlorobiphenyls are rapidly oxidated by electrogenerated $\mathrm{O}_{2}{ }^{--}$in aprotic media such as dimethylformamide, acetonitrile and dimethylsulphoxide. Consequently, it has been supposed the possibility of a reaction between PCBs and thermogenerated $\mathrm{O}_{2}{ }^{-}$in a closed system, in the presence of metallic ions able to act as acceptors of chlorine ions.

The aim of this research has been the setting-out of a method for a chemical mediate thermal disposal, suitable to operate at relatively low temperatures, avoiding the formation of secondary toxic molecules through undesired collateral processes. The final decomposition products have been monitored by analytical techniques, such as GC and coupled TG-FTIR, to optimize the reaction temperature.

\section{Experimental section}

\section{Materials and methods}

Hexachlorobenzene as the model system in the first instance, and decachlorobiphenyl as the target molecule representative of the PCB family were initially chosen. Samples of hexachlorobenzene in $10 \mathrm{ml}$ quartz phials (thickness $3 \mathrm{~mm}$ ) were mixed with barium peroxide in 1:40 hexachlorobenzene/ barium peroxide molar ratio; the phials were then sealed in oxygen atmosphere. A similar procedure was followed to prepare the decachlorobiphenyl samples.

The phials were then placed in a muffle furnace and heated following two complementary ways: leaving the phials for 10 minutes at different temperatures (respectively $650,750,850,950$ and $1000{ }^{\circ} \mathrm{C}$ ) and in isothermal mode for respectively 5,10 and 15 minutes to the chosen better performing temperature; the ampulles were then cooled at room temperature and opened; the residue was washed three times in known volumes of benzene to extract the residual halogenated hydrocarbons. The benzene fraction was analyzed by gas chromatography.

The solid mixture left after benzene extraction was dried under vacuum and subsequently analyzed by thermogravimetry (TG) also coupled to a FTIR spectrometer for the evolved gas analysis.

\section{Instrumental}

Gas chromatography was performed by DANI 3800 GC. Experimental conditions: capillary column SE 54, $0.32 \mathrm{~mm}$ internal diameter, $25 \mathrm{~m}$ long, $0.3 \mu$ film thickness; thermal gradient of $20^{\circ} \mathrm{C} \mathrm{min}-1$ from 60 to $250{ }^{\circ} \mathrm{C}$ after two minutes in isothermal mode.

Thermogravimetry was performed by a Perkin Elmer TGA7, heating rate of $10{ }^{\circ} \mathrm{C} \mathrm{min}-1$ under air or nitrogen dynamic atmosphere (flow rate: $100 \mathrm{~cm}^{3} \mathrm{~min}^{-1}$ ). The thermobalance was also coupled by a heated transfer line to a Perkin Elmer 1760X FTIR spectrometer equipped with a gas cell where the infrared spectra of the evolved gases were on line collected.

\section{Results}

In figure 1 the results of the gas chromatographic (GC) analysis of the benzene fractions obtained following the first heating method (10 minutes at different temperatures) are shown and compared with a not catalyzed oxidative decomposition process; the reacting temperature has consequently been chosen for both the models to be $950{ }^{\circ} \mathrm{C}$.

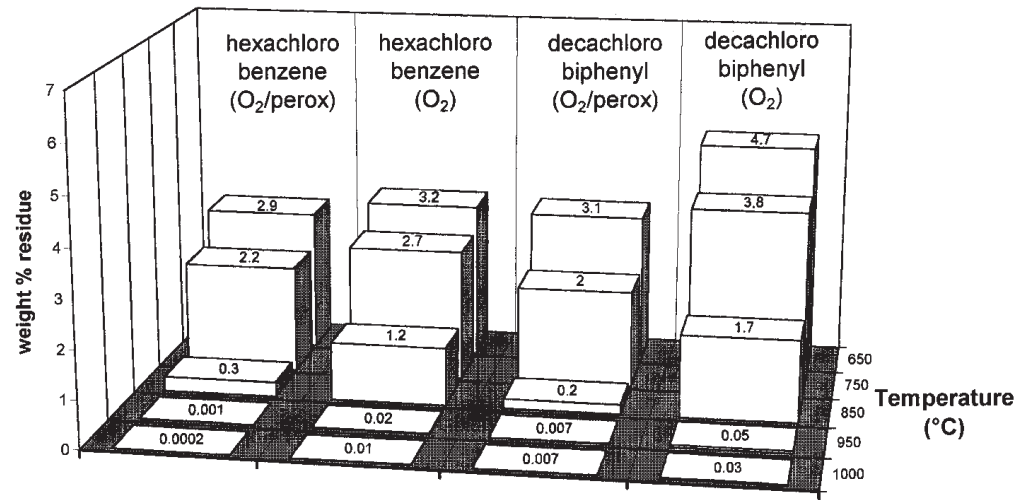

Figure 1. Residue of the initial sample after $10 \mathrm{~min}$ utes into the ampulles as a function of the muffle temperature. 


\section{Original articles}

\section{Hexachlorobenzene samples}

The GC analysis of the samples heated at $950{ }^{\circ} \mathrm{C}$ for $5 \mathrm{~min}$ utes shows the presence of oxygenated aromatic hydrocarbonic residues with low chlorine atom number and a considerable residue of unreacted hexachlorobenzene.

The samples heated for 10 minutes are still characterized by aromatic hydrocarbonic residues with low number of chlorine atoms and oxygenated residues, but the amount of unreacted hexachlorobenzene considerably decreases.

The 15 minutes heating process gives a more complete decomposition, with only traces of oxygenated polychlorobenzene in few samples, or total absence in the remaining samples.

The results are collected in figure 2 and compared with a not catalyzed oxidative decomposition process.

\section{Decachlorobiphenyl samples}

The GC analysis of the samples heated at $950{ }^{\circ} \mathrm{C}$ for $5 \mathrm{~min}-$ utes shows the presence of polychlorodibenzofurans with decachlorobiphenyl residue and traces of dioxin.

The samples heated for 10 minutes are characterized by a lower amount of polychlorodibenzofurans and decachlorobiphenyl with respect to the 5 minutes heated samples, by polychlorobyphenyls $(5 \leq \mathrm{Cl} \leq 9)$ and still traces of dioxin.

As for the hexachlorobenzene samples, the 15 minutes heating process is more performing, and only traces of polychlorodibenzofurans have been found by the GC analysis.

The results are collected in figure 3 and compared with a not catalyzed oxidative decomposition process.

\section{Solid residue}

The dry solid, left after the benzene extraction, was analyzed by thermogravimetry (TG) also coupled to a FTIR spectrometer for the evolved gas characterization. The TG curves related to the different residues and the infrared spectra of the gases evolved in the decomposition steps have been compared with the characteristic TG and coupled TG-FTIR profiles of standard barium salts to prove the presence of barium chloride and oxalate or carbonate. The coupled TGFTIR technique is extensively used in thermoanalytical characterization [47].

\section{Discussion}

The results obtained by the analysis of the benzene fractions and of the residues allow to assume that the involved reactions, according to Sugimoto et al. [48], are:

$$
\begin{gathered}
\mathrm{C}_{6} \mathrm{Cl}_{6}+12 \mathrm{O}_{2}{ }^{--} \Rightarrow 3 \mathrm{C}_{2} \mathrm{O}_{6}{ }^{2-}+6 \mathrm{Cl}^{-}+3 \mathrm{O}_{2} \\
3 \mathrm{C}_{2} \mathrm{O}_{6}{ }^{2-}+6 \mathrm{Cl}^{-}+6 \mathrm{Ba}^{2+} \Rightarrow 3 \mathrm{BaC}_{2} \mathrm{O}_{4}+3 \mathrm{BaCl}_{2}+3 \mathrm{O}_{2} \\
\mathrm{BaC}_{2} \mathrm{O}_{4} \Rightarrow \mathrm{BaCO}_{3}+\mathrm{CO}\left(\mathrm{CO}+\mathrm{O}_{2} \Rightarrow \mathrm{CO}_{2}\right)
\end{gathered}
$$

and

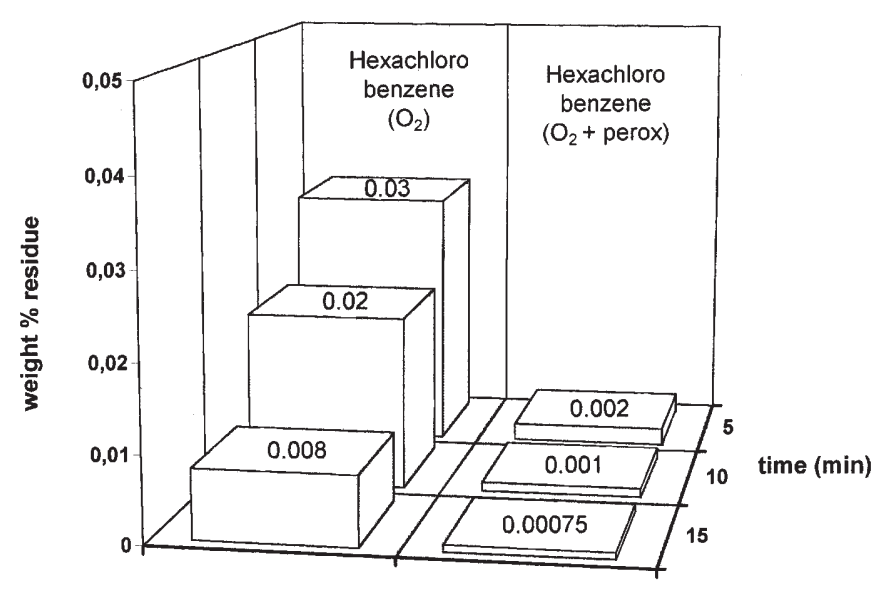

Figure 2. Hexachlorobenzene residue after thermal decomposition at $950{ }^{\circ} \mathrm{C}$.

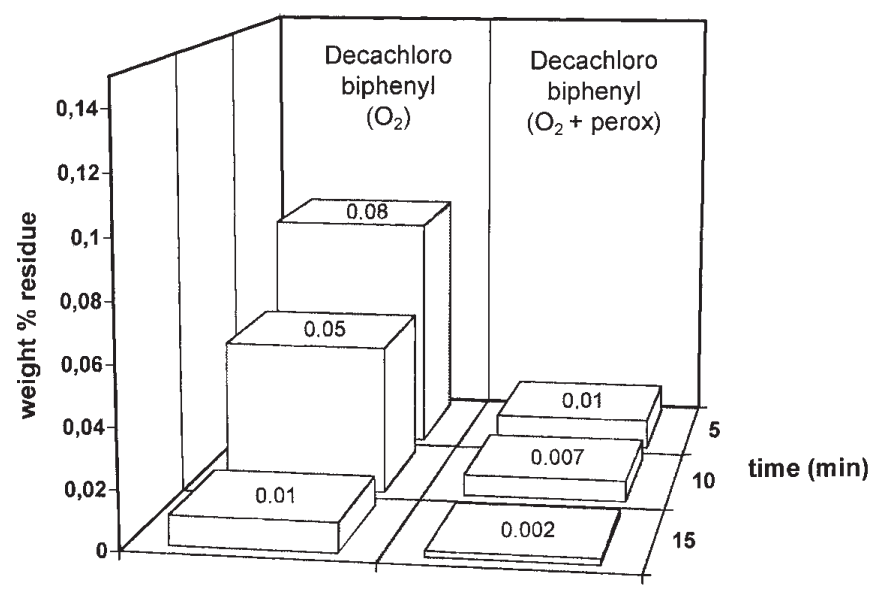

Figure 3. Decachlorobiphenyl residue after thermal decomposition at $950{ }^{\circ} \mathrm{C}$.

$$
\begin{gathered}
\mathrm{C}_{12} \mathrm{Cl}_{10}+22 \mathrm{O}_{2}^{\bullet-} \Rightarrow 6 \mathrm{C}_{2} \mathrm{O}_{6}{ }^{2-}+10 \mathrm{Cl}^{-}+4 \mathrm{O}_{2} \\
6 \mathrm{C}_{2} \mathrm{O}_{6}{ }^{2-}+10 \mathrm{Cl}^{-}+11 \mathrm{Ba}^{2+} \Rightarrow 6 \mathrm{BaC}_{2} \mathrm{O}_{4}+5 \mathrm{BaCl}_{2}+6 \mathrm{O}_{2} \\
\mathrm{BaC}_{2} \mathrm{O}_{4} \Rightarrow \mathrm{BaCO}_{3}+\mathrm{CO}\left(\mathrm{CO}+\mathrm{O}_{2} \Rightarrow \mathrm{CO}_{2}\right)
\end{gathered}
$$

The radical oxidation of hexachlorobenzene by thermal decomposition is proposed in the scheme 1 , where the initial step of the reaction is a nucleophilic addition of $\mathrm{O}_{2}{ }^{--}$to the polyhalobenzene. The subsequent loss of one chloride ion gives a benzoperoxy radical that interacts with a second $\mathrm{O}_{2}{ }^{--}$producing an orthoquinone and one chloride ion. The orthoquinone undergoes reaction with $\mathrm{O}_{2}{ }^{--}$to give peroxydicarbonate and chloride ions $[49,50]$. By thermal loss of $\mathrm{O}_{2}$ the peroxydicarbonate converts to oxalate which decomposes to $\mathrm{BaCO}_{3}$ stable up to $1100{ }^{\circ} \mathrm{C}$.

In order to verify the experimental conditions of the reacting mixture when introduced into the muffle, temperature 


\section{Original articles}

\section{Scheme 1}<smiles>Clc1c(Cl)c(Cl)c(Cl)c(Cl)c1Cl</smiles>
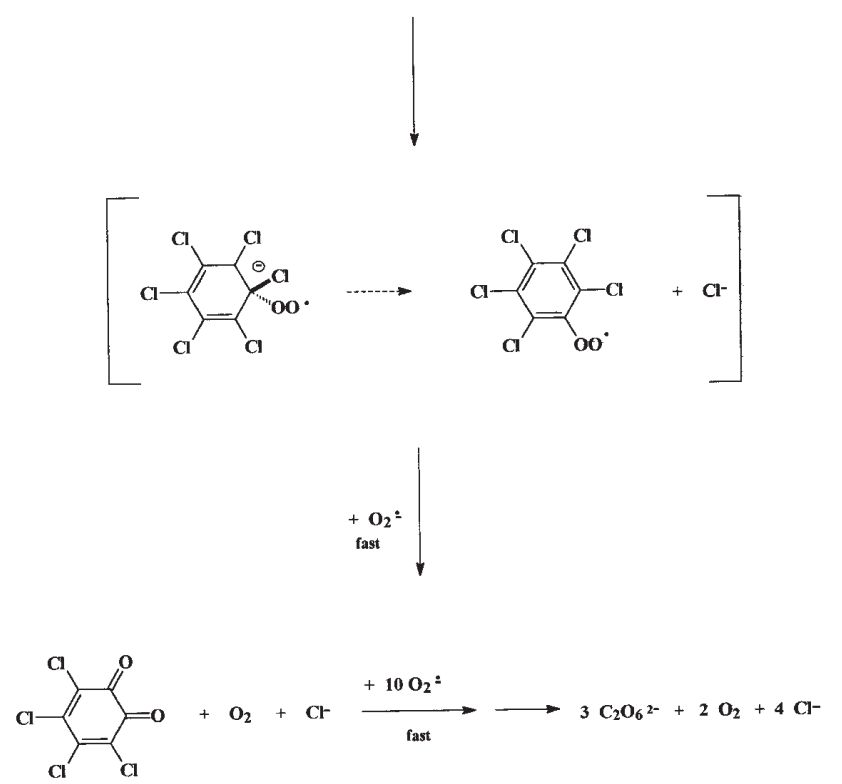

Total réaction : $\mathrm{C}_{6} \mathrm{Cl}_{6}+12 \mathrm{O}_{2}: \longrightarrow 3 \mathrm{C}_{2} \mathrm{O}_{6}{ }^{2-}+3 \mathrm{O}_{2}+6 \mathrm{Cl}^{-}$

tests were carried out by checking the melting of standard substances (potassium chromate, m.p. $670.5^{\circ} \mathrm{C}$; silver, m.p. $960.9^{\circ} \mathrm{C}$; etc.) into sealed phials. It was found that the temperature of $950{ }^{\circ} \mathrm{C}$ was reached about 4 minutes after the introduction in the muffle: the thermal reactions therefore occurred starting at lower temperatures and in a shorter time than expected. This fact explains the presence of barium oxalate in the 5 minutes heated samples: as enhanced by the TG profile and by the corresponding IR spectra of the TG evolved gases, the evolution of $\mathrm{CO}_{2}$ with oxidative flow (characteristic of the thermal decomposition of oxalate to carbonate, see figure 4) proves that the breakdown reaction is not completed after 5 minutes because the effective permanence time at $950{ }^{\circ} \mathrm{C}$ is shorter than scheduled and temperature gradients are present in the system. By increasing the permanence time at $950{ }^{\circ} \mathrm{C}$, the oxalate amount drastically decreases, being decomposed to carbonate during the reaction inside the ampulle.

These encouraging results prove that the proposed methodology is widely applicable, both for the reaction simplicity and for the short times involved; these considerations, as well as the energy saving due to the lower operational temperatures with respect to the usual thermodestruction, and the lower cost of catalysts, lead to believe that the contribution given to the solution of the considerable problem of waste is such that it will produce effective environmental benefits.

\section{Acknowledgments}

This researching project was supported by grants (40 and $60 \%$ ) from MURST of Italy.

\section{References}

1. Waid, J. in PCB's and The Environment; SRC Press: Boca Raton (FL), col.I-III 1986.

2. D'Itri, F.M.; Kamrin, M.A. Ann. Arbor Science Book; Boston, 1983.

3. Hutzinger, O.; Safe, S.; Zitko, V. in The chemistry of PCB's; CRC Press: Cleveland $(\mathrm{OH}), 1974$

4. Safe, S.; Bandiera, S.; Sawier, T.; Robertson, L.; Safe, L.. Parkinson, R.; Thomas, P.E.; Ryan, D.E.; Reik, L.M.; Levin, W.; Denomme, M.A.; Fujita, T. Environ. Health Perspect 1985, 60, 47.

5. Safe, S.; Crit. Rev. Toxicol. 1984, 13, 319.

6. Abenhaim, L. Poll. Atm. 1985, Oct-Dec, 248.

7. Kimbrough, R.D. Crit. Rev. Toxicol. 1974, 2, 445.

8. Fischbein L. Ann. Rev. Pharmacol. 1974, 14, 139.

9. McConnell, E.E.; Moore, J.A. Ann. N.Y. Acad. Sci. 1979, 320, 138.

10. Carpenter, B.H. EPA/600/59-86/112 March 1987.

11. Karasek, F.W.; Dickson, L.C. Science 1987, 237, 754.

12. Jordan, O.D. U.S. Patent 4340471, 1982.

13. Norman, L.O. U.S. Patent 4379752, 1983.

14. Pytlewski, L.L.; Krevitz, K.; Smith, A.B.; Thorn, E.J.; Iaconiani, F.J.; "Abstracts of papers", EPA treatment of hazardous waste, 6th Resaearch Symposium, Chicago (IL), 1980.

15. Iaconiani, F.J.; PCB, Diss. Abstr. Int. B. 1983, 44, 1456.

16. Pytelewski, L.L.; Iaconiani, F.J.; Krevitz, K.; Smith, A.B. U.S. Patent 4417977, 1983.

17. Brown, J.F.; Lynch, M.E.; Carnahan, J.C.; Singleton, J. "Abstracts of Papers", 182nd National Meeting of the Am. Chem. Soc. N.Y., 1981.

18. Smith, J.G.; Bubbar, G.L. "Abstracts of Papers" 182nd National Meeting of the Am. Chem. Soc. N.Y., 1981.

19. Brunelle, D.J. Environ. Sci. Technol. 1985, 19, 740.

20. Sugimoto, H. PCB, Environ. Sci. Technol. 1988, 22, 1182.

21. Vrana, B.; Dercova, K.; Balaz, S. Biotechnol. Tech. 1995, 9 , 333

22. Vollmuth, S.; Niesser, R. Chemosphere 1995, 30, 2317

23. Arbon, R.E.; Mincher, B.J.; Knighton, W.B. Environ. Sci. Technol. 1996, 30, 1866

24. Taniguchi, S.; Miyamura, A.; Ukisu, Y.; Marakami, A.; Hosomi, M. Organohalogen Compd. 1995, 26, 411

25. Koller, G. Moder, M.; Mattusch, J.; Czihal, K.; Engewald, W.; Organohalogen Compd., 1996, 29, 476

26. Pitea, D. Tecnol.Chim. 1991, 11, 154

27. Yamazi, T.; Miue, Y.; Seto, S. Patent 92279178/A62D003/00/B01J-019/08.

28. Rossi, C.; Nelis, P. Patent 1003331/A62D-003/00/C10M175/00.

29. Bressa, G. Dif. Ambientale 1992, 16, 60

30. Irie, T.; Isogai, K. Patent 9384324/A62D-003/00/B09B003/00.

31. Sato, C.; Leung, S.W.; Bell, H.; Burkett, W.A.; Watts, R.J. ACS Symp. Ser. 1993, 518, 343. 


\section{Original articles}
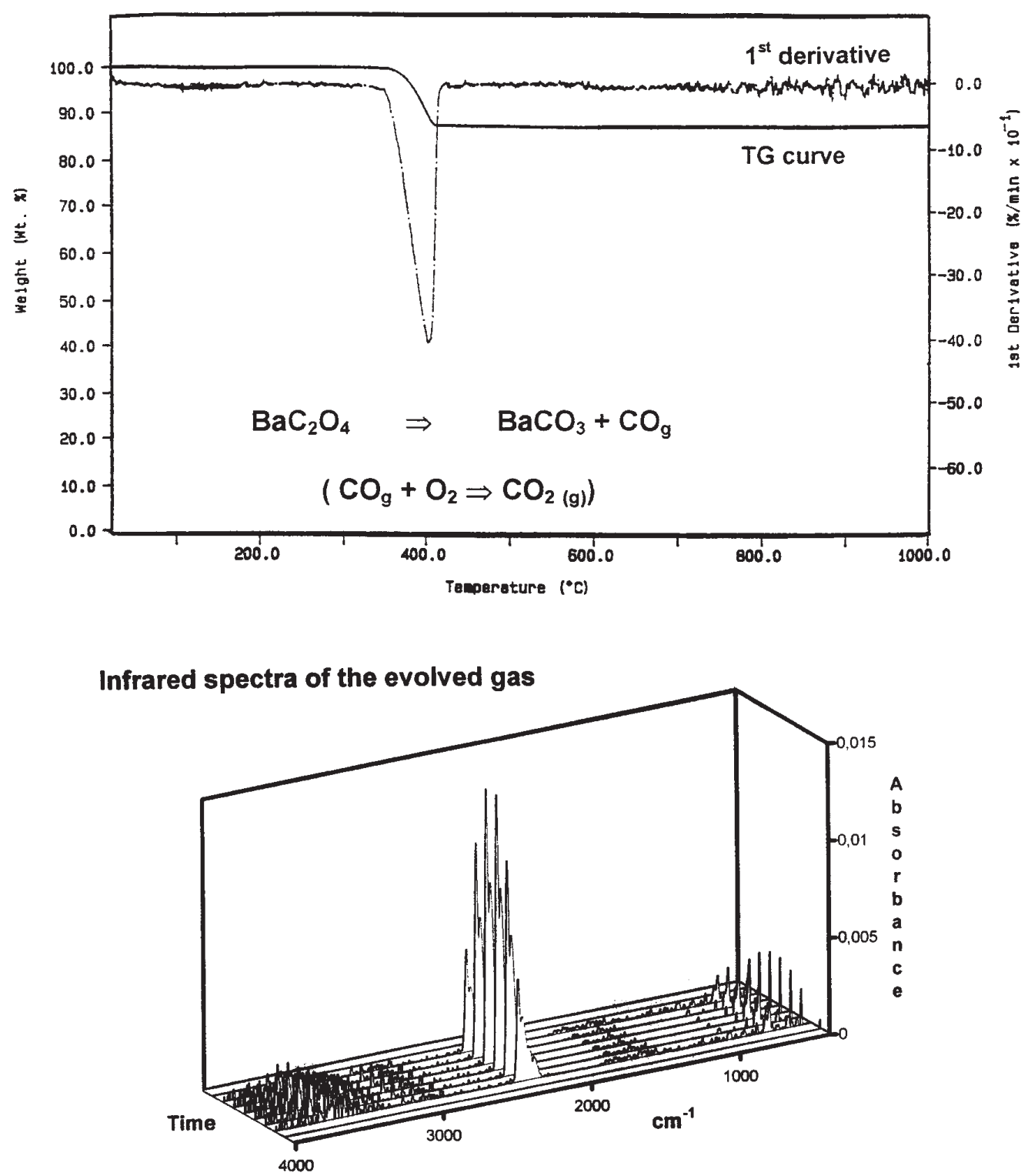

Figure 4. a) Thermogravimetric profile of the solid residue after 5 minutes at $950{ }^{\circ} \mathrm{C}$ or 10 minutes at $650{ }^{\circ} \mathrm{C}$. Barium oxalate is present because of the thermal gradients into the ampulles; b) Infrared spectra of the gas evolved during the TG process. The bands prove the release of $\mathrm{CO}_{2}$.

32. Watanabe, M.M.; Kenmochi, S.; Shoji, J. Patent 93177188/C02F-001/58/B01J-019/00.

33. Chan, D.B.; Yeh, S.L. Proc. Ann. Meet. Air Waste Manage. Assoc. 1992, 85, 92.

34. Ocker, H.D. Angew. Wiss. 1993, 418, 5.

35. Tanimoto, F.; Yano, T. Patent 9500207/A62D-003/00/B09B003/00.

36. Zhao, Y.; Wang, Z.; Li, H. Hebei Daxue Xuebao 1995, 15, 31.

37. Vodichka, L.; Hlavaty, J.; Burkhard, J. Chem. Prum. 1995, 45, 148.

38. Seppa, R.U.I.; Engelbrecht, W.J.; Hearn, I.R.; Van Staden, G.F.; David, F. Patent 9524945/A62D-003/00.

39. Kawahara, F.K.; Michalakos, P.M. Ind. Eng. Chem. Res. 1997, 36,1580 .

40. Taniguchi, S.; Miyamura, A.; Ebihara, A.; Marakami, A.; Hosomi, M.; Organohalogen Compd. 1996, 27, 105.
41. Taniguchi, S.; Miyamura, A.; Marakami, A.; Hosomi, M. Chemosphere 1997, 34, 1631.

42. Chan, D.B.; Yeh, S.L. Contam. Soils 1996, 1, 259.

43. Yabuki, M.; Sakai, K.; Tanaka, A.; Endo, H. Patent 97253478/B01J-019/00/A62D-003/00.

44. Wachs, I.E.; Madix, R.J. Surf. Sci. 1978, 76, 531.

45. Wachs, I.E.; Madix, R.J. Appl. Surf. Sci. 1978, 1, 303.

46. Wachs, I.E. J. Catal. 1978, 53, 208.

47. Materazzi, S. Appl. Spectr. Rev. 1997, 32, 385

48. Sugimoto, H.; Matsumoto, S. J. Am. Chem. Soc. 1987, 109, 8081.

49. Sawyer, D.T.; Stamp, J.J.; Menton, K.A. J. Org. Chem. 1983, 48, 3733.

50. Roberts, J.L.; Sawyer, D.T. J. Am. Chem. Soc. 1984, 106, 4667. 